\title{
The Governance Enterprise Architecture (GEA) High-Level Object Model
}

\author{
Vassilios Peristeras $^{1}$ and Konstantinos Tarabanis ${ }^{2}$ \\ ${ }^{1}$ National Centre for Public Administration, Koletti 25D, Thessaloniki, Greece \\ per@untcentre.org \\ ${ }^{2}$ University of Macedonia, Egnatias 156, Thessaloniki, Greece \\ kat@uom.gr
}

\begin{abstract}
In this paper, we continue our work on building the Governance Enterprise Architecture (GEA) by proposing the GEA high-level object model for the overall governance system. The core concepts of the model emerged by utilizing a metaphor: administration and society interacting in a linguistic way. The model elaborates on this isomorphism (common structural artifacts) between the two systems: language and public administration. Based on this metaphor, the object model is built both with regard to its structure (object classes, relationships, inheritance) and its contents.
\end{abstract}

\section{Introduction - Motivation}

During the last decade, there have been several attempts, in various industries, proposing high-level domain specific models [1-6], which aim at describing the overall domain under study. The derived models could be used as blueprints for analysis, system design and implementation. Moreover, they could constitute a common language thus providing a means of communication amongst units or even a means of representing knowledge for use in the industry as a whole. The same need has led IT vendors such as SAP [7] and IDS Scheer [8] to formulate ready-to-configure solutions covering specific industries and creating generic industry process and data models.

In public administration relevant initiatives are rather rare. A brief description of the more important follows:

The U.S. Vice President's office of the National Performance Review together with the Inter-Agency Benchmarking \& Best Practices Council supported the development of a government process classification framework. This framework proposes four major processes for all public administration agencies: "Establish Direction", "Acquire Resources", "Provide Capabilities" and "Execute the (Agency's) Mission". These are further analysed providing over 150 lower level processes [9].

Following a similar approach, the recent Business Reference Model, as introduced by the Federal Enterprise Architecture Program Management Office in the USA, has defined four different core business areas. These areas separate government operations into high-level categories relating to the purpose of government (Services for Citizens), the mechanisms the government uses to achieve its purpose (Mode of Delivery), the support functions necessary to conduct government operations (Support Delivery of Services), and the resource management functions that support all areas of 
the government's business (Management of Government Resources). These highlevel areas are further analysed in 39 "Lines of Business" and 153 "Sub-Functions" covering the overall federal enterprise [10].

In the UK, the e-Envoy Office proposed as part of the e-Services Development Framework [11], the Government Common Information Model (GCIM) which is a generic data model representing the basic entities and relationships during the Service Interaction phase. These entities identified to be: "Rule", "Service", "Location", "Evidence", "Outcome" and "Subject"[12].

These national initiatives have developed descriptions and models based on and addressing specific needs of the broader projects they were part of. As a result, they were focused on providing solutions to local problems and not to develop models to be accepted on a wider basis. For this reason, they were not adopted or exploited by a wider community outside the country they were proposed. An additional limitation of these approaches has been that they were focused only on the part of the overall administrative domain that is related to "service provision". Identifying the overall governance domain with service provision excludes important aspects and parts of the overall governance system such as the society-to-political system interaction.

Attempting to address the problem regarding the lack of holistic domain models for the overall governance system, during the last years we have created the Governance Enterprise Architecture (GEA). At the current stage of development, GEA consists of four high-level models:

- The GEA mega-process model of the overall governance system [13].

- The GEA interaction model of the overall governance system [14].

- The GEA public policy formulation object model (strategic planning) [15].

- The GEA service provision object model [12].

Advancing our domain analysis, we present here the latest development of our work: the GEA high-level object model for the overall governance domain.

\section{Overall Presentation of the GEA Object Model}

The GEA object model has been derived in a top-down fashion. The basic model's entities, instances, and relationships emerged by employing a metaphor in describing the governance system: we used the metaphor of language, and we consider the relationship between administration and society in a linguistic context [16].

The model (Fig.1) depicts the main objects and relationships that constitute the overall governance system. That is, it covers the path that leads from the conceptualisation of administrative action to the realization and process execution in the real world, in correspondence with the "Formulate Public Policy" and the "Provide Service" mega-processes of our GEA mega-process model [13].

As can been seen in Fig.1, we have included instances in some of the model's objects. In some cases, these instances serve simply as examples (e.g. at the Public Service object). Though, in the case of the "Administrative Function" and "Type of Public Service", we propose important, exhaustive populations of the entities. As these are of particular interest for our domain analysis, we present them separately in Sections 3.2 and 3.3, respectively. The primary entities and the underling relation- 
ships of the model are depicted in Fig. 1. A description follows, starting from the right side of the model.

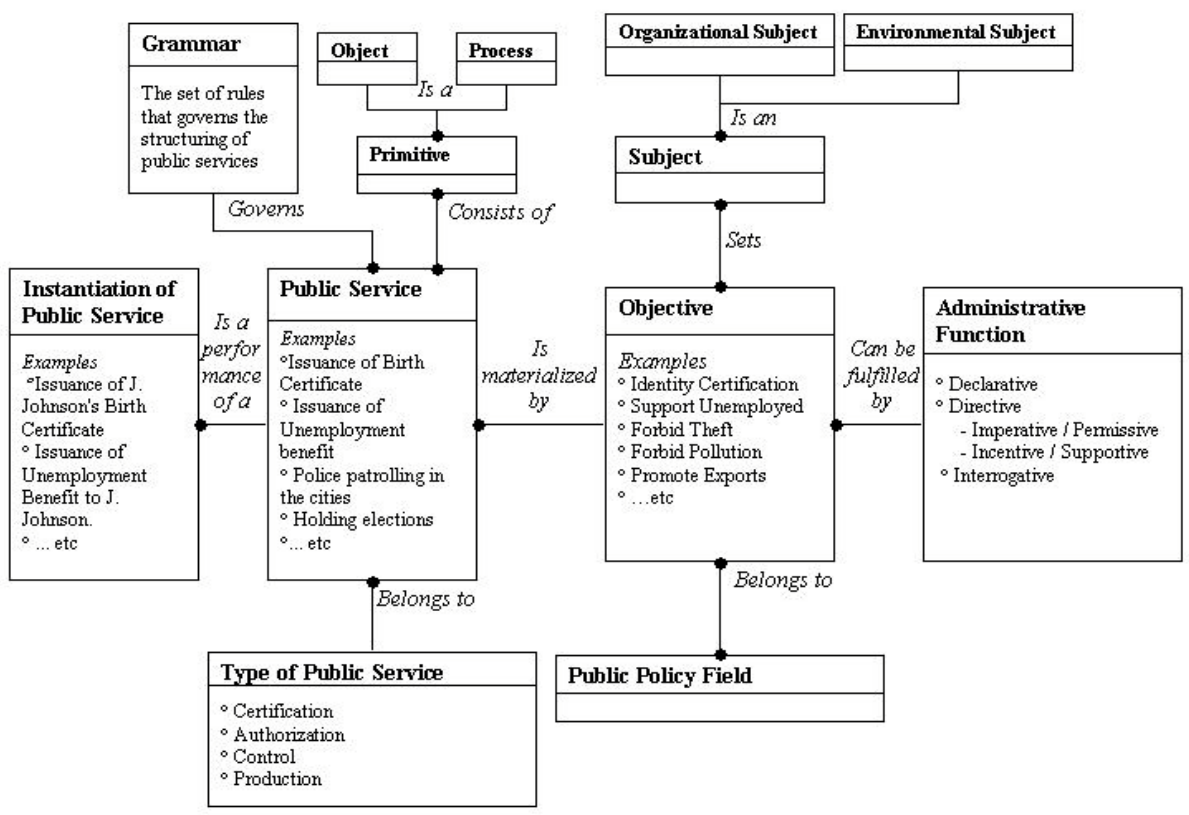

Fig. 1. The GEA object model for the overall governance system

Administration performs a set of primary Functions. At a high level there are three types, as derived by the linguistic metaphor we employed. In the society - administration "conversation", there are three types of interaction: Declarative, Directive and Interrogative. The directive administrative function is further broken down into two categories: Imperative/Permissive and Incentive/Supportive.

Administration sets Objectives to be reached. By doing so, administration chooses from a superset of potential objectives, the subset to be realized. Objectives are related to the abovementioned three primary Functions. They are politically defined, and administration sets them as targets to meet.

Objectives are linked to several Public Policy Fields. The latter are defined as functional areas of Public Policy interest. These Public Policy Fields are more or less close to the departmentization introduced to administrative space by ministries.

In order to materialize the Objectives, administration has to organize and to provide Public Services. We identify four primary types of Public Services: certification, authorization, control and production.

It is very important for the comprehension of the model to distinguish between "Types of Public Services" and "Types of Administrative Functions". Although a strong link exists between the two, each Administrative Function is realized alternatively by all Types of Public Services. So a single Objective can be attained through a number of different Public Services. The choice each time of the specific Public Service, through which Administration will reach the satisfaction of an Objective, de- 
pends on various factors, such as the administrative capacity, the information technology available, the existing organizational and institutional infrastructure, etc.

Public Services are considered to consist of Objects and Processes (here called Primitives). Their appropriate organization is governed by a set of structural rules, which could be called (administrative) Grammar.

Public Services are described here as abstract entities. They are units of the administrative system they belong to. What is finally performed in the real world is just the Instantiations of these Public Services. Both the Service and its Instantiation can be perceived either as a process or as a product. The meaning of each Instantiation is richer than the meaning of the Public Service from which it derives. Instantiations consist of the abstract models (Public Service) together with all the intonations of the real world (space, time, real people, behaviour, culture, etc). What finally reaches the citizen is the Instantiation and not the Public Service. For each Public Service, we have numerous real world instantiations.

\section{Administrative Function}

All systems perform a set of primary functions. In the case of the governance system an interesting question can be posed: What are the categories of administrative action that the governance system performs?

Researchers of administration usually address this question proposing classifications along various lines [17-19]. One of the more common is based on the functional notion of the public policy field. In this line, administrative function is classified in categories such as securing the existence of the state and internal order, promoting economic growth and welfare of the society, etc.

Although useful for practical purposes, this classification of administration action is not sufficient, as it demonstrates more the variety of the fields in which administrative action can be applied and not the different nature of this action per se. Thus, this taxonomy lies at the surface and cannot appropriately address the posed question.

Getting insights from linguistics [16], we tried to identify primary functions performed by administration during its communication with society. We propose three primary administrative functions, in line with the three basic communication functions of the language:

- Declaration

- Direction

- Interrogation

The Interrogative function corresponds to the upward movement of information from society to decision-makers, while the Declarative and Directive functions correspond to the downward movement of the political decision to the administrative system, and society. The latter functions lie at the top of our domain analysis, thus clarifying their characteristics is critical. A description of these two functions follows in the next sub-sections. We will not elaborate further on the Interrogative function here. 


\subsection{Declarative Function}

Through the Declarative function, administration declares and certifies the existence and the truth of certain world states. Thus, this function is referential and descriptive. It is uttered by administration in declarative mood. The logical pattern describing the declarative function is "Certifying X for Entity Y" (e.g. certifying J. Johnson's family status or place of birth).

Why does society need the administration to certify states of the world? Social entities need to interchange certified information. There are several possible ways to certify a piece of information. Depending on the importance of each particular case, these may include a declaration of the individual (e.g. official income declaration for tax authorities), a third party certification (notary, lawyer) and for more critical information an official certification from a public agency. Administration is considered to be the most reliable certification actor in society: a kind of "honest broker" arbitrating private transactions in a neutral manner. Nowadays, administration certifies an extended set of information related to citizens or enterprises.

\subsection{Directive Function}

Through the Directive function, administration directs society to certain states. Thus, this function is constructive and deontological.

The Directive function can be further decomposed into two types, describing the two paths administration uses to direct society:

- Imperative - Permissive

- Supportive

The first refers to administrative action that gives direction to the society by command. The second gives direction through incentives and support.

\subsubsection{Imperative - Permissive}

As Imperative, we define the set of functions through which the administration forces or forbids societal behaviours. These functions are uttered by administration in an imperative mood and society owes mandatory compliance and obedience.

In administration the prevailing position of the Imperative function is justified on historical, significance and frequency grounds.

The Imperative function can be further decomposed into two types, depending on whether the administration forbids or forces the subject to have specific behaviour. We call the first kind of functions "prohibitions" and the latter "obligations".

- Prohibition. The state prohibits behaviors for many different reasons. What is prohibited each time in society depends on various socio-political factors that change in time. The prohibition has a clear negative connotation: the subject should avoid specific behaviors.

- Obligation. On the other hand, the state sometimes demands specific behaviors and forces the society to obey certain patterns (e.g. mandatory education up to an age). Although an obligation can derive as the alternative, opposite view of a prohibi- 
tion, the first in contrary with the latter has generally a positive connotation: the subject should follow specific behaviors.

In another dimension, two categories of the Imperative function result as follows:

- Absolute command, when the prohibition (or obligation) is general and without exceptions (e.g. theft, kidnap, rape)

- Conditional command, when the prohibition (or obligation) can be lifted under specific circumstances (e.g. not to drive without a driver's license, not to build without a building license).

The latter category of Imperative functions acquires special interest for the administration, as it is the basis for the Permissive administrative function.

We define as Permissive the set of functions through which the administration recognizes special rights and allows behaviours otherwise prohibited. Through the Permissive function, exceptions are activated in situations where a universal prohibition has been enforced. These functions are also uttered by administration in an imperative mood, as administration sets a mandatory process that has to be followed if the subject wants to exercise this kind of behaviours. The Permissive function can be perceived as a special case of the Imperative one, as it directly relates to command under conditions [16]. The logical pattern describing the permissive function is " $\mathrm{X}$ is prohibited, unless Y occurs" (e.g. building a house is prohibited, unless you have a building license).

Why does society need the administration to assign special rights and decide exceptions to universal prohibitions? From the first time administration posed certain prohibitions to society through its imperative function, we can assume that the need for exceptions emerged. Even if these exceptions could be assigned ad-hoc, administration sooner or later faced the problem of better organizing the process of "exceptions". The generalized use of this practice resulted in the appearance of the Permissive function.

\subsubsection{Supportive}

In this broader category, we group functions through which the administration offers guidance and support to society. These functions are uttered by administration in an incentive mood, as compliance is not mandatory (optional).

Through the supportive function, administration either promotes specific behaviours or assists the society, providing basic infrastructures, goods and services.

Why does society need these supportive functions to be provided by the administration? As described in contemporary macro-economic theory, there are several types of inconsistencies that the market mechanism cannot resolve automatically, to the contrary of what was initially declared by the classical liberal approach. These inconsistencies are related to social and macro-economic issues (e.g. income distribution, production of public goods and infrastructure).

Administration takes action in these cases in order to support the (macro) economic development of the society and the citizens with low income. Historically, administration developed these functions with the emergence of the Welfare State.

In the Figure that follows, we present the different types of the Support function. 


\section{A. Support Function}

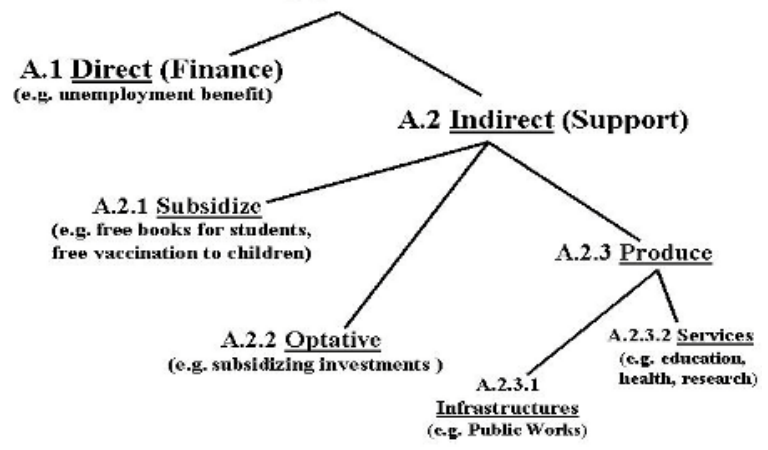

Fig. 2. The types of Support Functions

The Support function can be either Direct (A.1) through financing actors with few financial means (giving money, which means financing consumption) or Indirect (A.2). There are three types of Indirect support:

- Subsidize (A.2.1): Subsidizing access to goods and services that are considered as vital and for which exclusion is considered unacceptable (e.g. subsidization to keep low fares for urban public transportation, for museum entrance, for covering a percentage of operational costs of kindergartens). The production of these goods and services remain with the private sector.

- Optative (or Incentive) (A.2.2): Through the Optative Function, administration promotes specific behaviors. To persuade and urge society towards these behaviors, administration offers support as an impetus (e.g. subsidizing investments, providing bonus for having a third child or for employing unemployed persons).

- Produce (A.2.3): There is an important type of indirect support, due to its size in modern states, when administration offers for free (or below the production cost) infrastructures, products and/or services that have been produced internally (e.g. public hospitals, public schools). The infrastructures and services selected for production are usually those considered as "public goods". The inner motivation for this production is the same as with "Subsidize". For effectiveness and efficiency reasons administration decides not simply to subsidize the access to these services, but to undertake the overall control and produce them using internal resources.

\section{Objective}

In language, speakers want to communicate messages to other entities. The speaker usually utters sentences to communicate these messages. In an analogous sense, administrations want to fulfil certain objectives. Administrations perform public services to fulfil these objectives.

Communicating effectively the message is a target for the speaker. Several different sentences of different types can be used alternatively and even the very same sentence can be uttered in very different styles and moods. Similarly, fulfilling certain 
objectives is a target for administrations. Several different public services can be performed in the quest to meet a specific target.

The process of defining objectives (issue filtration and agenda setting [20]) is quite complicated in public policy since drafting objectives is directly linked to the process of realizing them [21]. Nevertheless, administration comes up with a concrete list of objectives to pursue, regardless of the difficulties encountered to draft this list. The administrative objectives are defined both on an historical and a geographical basis.

Objectives are ideas, which administration sets as policy targets. In order to meet these targets, administration must organize an implementation mechanism. This mechanism has to transform vision into action and practically results in an extended set of public services.

As shown in the model, each objective is related to one and only one administrative function, while each administrative function is associated with a number of objectives (one-to-many relationship). Additionally, administration can alternatively deploy a variety of public services, in order to fulfil an objective. Different objectives may not be achieved through the same public service (one-to-many relationship).

Objective is the connecting entity between administrative function and public service, as can be seen in Fig.1. It serves as an intermediate entity between the abstract administrative function and the "down-to-earth" public service.

\section{Public Service}

Modern administrations, in the quest to address the ever-evolving social needs, produce a wide spectrum of services that currently covers almost every aspect of the citizen's life. Each different public administration chooses and orchestrates a different set of public services in order to fulfil the selected objectives.

Can we classify the hundreds of public services provided by administrations into general types with common characteristics? By addressing this question, we then can identify generic types of public services with similar characteristics. These generic types could be described once and these descriptions could then be used either to analyze existing or to create new instances of services by just reconfiguring the generic types appropriately. A generic process model could also be proposed for each type of public service.

In our work, we have identified four generic types of public services:

- Certification: There is a prevailing (characteristic) type of public service for fulfilling the Declarative function and this is "Certification". Through certifications administration declares and certifies different states of the world.

- Control: How do administrations realize the Imperative function, through which it either prohibits or forces specific behaviors upon society? Administration has to secure that society adheres to prohibitions and obligations. The main role of public administration in this case is to "Control". As the offender tends to hide his behavior from the administration, the most ordinary type of this administrative action is inspections on a periodic or on an impromptu basis.

- Authorization: There is a prevailing type of public service through which administration realizes both the Permissive and the Support function, and this is "Authorization". Administration sets up an entire mechanism, to exercise this type of serv- 
ices. In case special conditions are met, either the universal prohibitions should be withdrawn (permissive) or a support should be awarded (supportive).

- Production: In Section 3, Production has been identified as a sub-type of Supportive administrative function. Public administration must organize a "Production" mechanism internally.

In Table 1, we present the correspondence between administrative functions and the type of public services, which are typically (or characteristically) employed.

Table 1. Characteristic types of Public Service for Administrative Functions

\begin{tabular}{|l|l|}
\hline Administrative Function & Characteristic Type of Public Service \\
\hline Declarative & Certification \\
\hline Imperative & Control \\
\hline Permissive & Authorization \\
\hline Supportive & Authorization \\
\hline Production & Production \\
\hline
\end{tabular}

Although a strong (characteristic) link exists between administrative functions and types of public services, each function can be realized by many types of public services. This statement has many consequences in our overall domain model.

We demonstrate this "multiplicity" feature between functions and public services using an example (Table 2).

Table 2. Multiplicity in "Administrative Functions - Public Services" relationship

Objective: Prohibition of
Administrative Function: Directive, Imperative

a. Instance of Public Service $=$ Periodic control of pollutant emission from factory flues

Type of Public Service $=$ Control

b. Instance of Public Service $=$ Issuance of operating licenses for factories

Type of Public Service $=$ Authorization

c. Instance of Public Service $=$ Issuance of a certificate asserting that no pollution is caused

Type of Public Service $=$ Certification

\section{Conclusion - Future Work}

In this paper, we overview the GEA high-level object model for the overall governance system. There are still parts and aspects of the models, which need further analysis. The difference between "public service" and "instantiation" and the notion of the "administrative grammar" are indicative examples.

Furthermore, we plan to analyse the four generic types of public services, with the intention to identify and reduce them into "primitive components" (or building blocks). Through this path of work, we intend to come up with more detailed descriptions for the processes executed in the "Provide Service" mega-process.

Last, we intend to better "tune" all the GEA models in order to better align all the concepts presented in them, enforce the existing interrelations and strengthen the overall GEA consistency. 
Acknowledgements. This work has been partially funded by the IST-2001-35217 project "EU-Publi.com". Peristeras Vassilios is a scholar of the State Scholarships Foundation of Greece.

\section{References}

1. Association for Retail Technology Standards, ARTS Retail Store Integrated Business View Data Model. 1995.

2. Supply Chain Organization, Overview of the SCOR Model v3.0, 1998, at www.supplychain.org, accessed in Nov. 1999

3. IBM, Retail pplication Architecture (RAA) / General Information Manual. 1993.

4. Uschold, M., et al., The Enterprise Ontology. The Knowledge Engineering Review, Special Issue on Putting Ontologies to Use, 1998. 13 (1).

5. Silverstone, L., W.H. Inmon, and K. Graziano, The Data Model Resource Book. 1997: John Wiley \& Sons, Inc.

6. Hay, D., Data Models Patterns. 1996, NY: Dorste House Publishing.

7. SAP, R/3 System SAP Solution Map, at www.sap.com, accessed in Dec. 2000

8. IDS Scheer, ARIS Toolset, at www.ids-scheer.de, accessed in Dec. 2000

9. Inter-Agency Benchmarking \& Best Practices Council, Government Process Classification Scheme, 1996, available at http://www.va.gov/fedsbest/index.htm, as accessed in Dec. 2001

10. The Federal Enterprise Architecture Program Management Office, The Business Reference Model Version 2.0. 2003.

11. Office of e-Envoy UK, e-Services Development Framework Primer v1.0b, 2002, at http://www.govtalk.gov.uk/documents/eSDFprimerV1b.pdf, accessed in Noe. 2002

12. Tarabanis K. and Peristeras V., Knowledge Management Requirements for Pan-European Public Administration Service Delivery, in Knowledge Management in Electronic Government: 4th IFIP International Working Conference, KMGov 2003, Rhodes, Greece, May 26-28, 2003. Proceedings. 2003, Springer-Verlag Heidelberg: Rhodes Island, Greece.

13. Tarabanis, K. and V. Peristeras, Towards an Enterprise Architecture for Public Administration: A Top Down Approach. European Journal of Information Systems, 2000. 9 (Dec. 2000): pp.252-260.

14. Peristeras, V., T. Tsekos, and K. Tarabanis. Building Domain Models for the (e-) Governance System. In International Conference on Politics and Information Systems: Technologies and Applications (PISTA '03). 31 Jul.-2 Aug., 2003. Orlando, Florida, USA.

15. Tarabanis, K., V. Peristeras, and G. Fragidis. Building an Enterprise Architecture for Public Administration: A High Level Data Model for Strategic Planning. In 9th European Conference on Information Systems. June 2001, Bled, Slovenia.

16. Peristeras V. and Tarabanis K., Analyzing Public Administration Using a Linguistic Metaphor. 2003, University of Macedonia: Thessaloniki.

17. Lowi, T.J., The End of Liberalism: The Second Republic of the United States. 1979, New York: W.W. Norton.

18. Lane, J.-E., The Public Sector: Concepts, Models and Approaches. 2nd ed. 1995: Sage Publications.

19. Musgrave, R.A., The Theory of Public Finance. 1959, New York: McGraw-Hill.

20. Hogwood, B.W. and L.A. Gunn, Policy Analysis for the Real World. 1984, Oxford: Oxford University Press.

21. Browne, A. and A. Wildavsky, Should Evolution become Implementation. 1984: Pressman and Wildavsky. 